\title{
Intraocular Pressure Fluctuations and 24-Hour Continuous Monitoring for Glaucoma Risk in Wind Instrument Players
}

Citation for published version (APA):

de Crom, R. M. P. C., Webers, C. A. B., van Kooten-Noordzij, M. A. W., Michiels, A. C., Schouten, J. S. A. G., Berendschot, T. T. J. M., \& Beckers, H. J. M. (2017). Intraocular Pressure Fluctuations and 24-Hour Continuous Monitoring for Glaucoma Risk in Wind Instrument Players. Journal of Glaucoma, 26(10), 923928. https://doi.org/10.1097//JG.0000000000000747

Document status and date:

Published: 01/10/2017

DOI:

10.1097/IJG.0000000000000747

Document Version:

Publisher's PDF, also known as Version of record

Document license:

Taverne

Please check the document version of this publication:

- A submitted manuscript is the version of the article upon submission and before peer-review. There can be important differences between the submitted version and the official published version of record.

People interested in the research are advised to contact the author for the final version of the publication, or visit the DOI to the publisher's website.

- The final author version and the galley proof are versions of the publication after peer review.

- The final published version features the final layout of the paper including the volume, issue and page numbers.

Link to publication

\footnotetext{
General rights rights.

- You may freely distribute the URL identifying the publication in the public portal. please follow below link for the End User Agreement:

www.umlib.nl/taverne-license

Take down policy

If you believe that this document breaches copyright please contact us at:

repository@maastrichtuniversity.nl

providing details and we will investigate your claim.
}

Copyright and moral rights for the publications made accessible in the public portal are retained by the authors and/or other copyright owners and it is a condition of accessing publications that users recognise and abide by the legal requirements associated with these

- Users may download and print one copy of any publication from the public portal for the purpose of private study or research.

- You may not further distribute the material or use it for any profit-making activity or commercial gain

If the publication is distributed under the terms of Article $25 \mathrm{fa}$ of the Dutch Copyright Act, indicated by the "Taverne" license above, 


\title{
Intraocular Pressure Fluctuations and 24-Hour Continuous Monitoring for Glaucoma Risk in Wind Instrument Players
}

\author{
Ronald M.P.C. de Crom, MD, * Carroll A.B. Webers, MD, PhD,* \\ Marina A.W. van Kooten-Noordzij, MD, $\dagger$ Agnes C. Michiels, MD, $\neq$ \\ Jan S.A.G. Schouten, MD, PhD,* Tos T.J.M. Berendschot, PhD, * \\ and Henny J.M. Beckers, MD, PhD*
}

\begin{abstract}
Purpose: The purpose of this study is to investigate the influence of playing a wind instrument on intraocular pressure (IOP) and to monitor 24-hour (IOP) fluctuations in wind musicians of symphony and wind orchestras to compare IOP levels during normal daily activities with IOP levels during playing.
\end{abstract}

Methods: Professional and amateur musicians of symphony and wind orchestras were invited to participate. A total of 42 participants, 9 with glaucoma, underwent a routine ophthalmologic examination. IOP measurements were taken before and immediately after 20 minutes of playing wind instruments. In addition, 6 participants underwent 24-hour IOP monitoring with the Triggerfish (Sensimed AG, Switzerland) sensing contact lens, during which they kept an activity logbook.

Results: Eleven professionals and 31 amateur musicians participated in the study. A total of 7 eyes of 6 patients underwent additional 24-hour IOP monitoring. Mean IOP before playing was $13.6 \pm 2.6 \mathrm{~mm} \mathrm{Hg}$, IOP change after playing was $+1.5 \pm 2.2 \mathrm{~mm} \mathrm{Hg}$ with a significant difference between professionals $(2.5 \pm 1.5 \mathrm{~mm} \mathrm{Hg})$ and amateurs $(1.1 \pm 2.3 \mathrm{~mm} \mathrm{Hg})$. There were no significant differences in IOP change between subjects with or without glaucoma. During 24-hour IOP monitoring there were slight increases in IOP while playing an instrument, but also during other activities and overnight. These latter IOP levels were similar or even higher than the IOP rise caused by playing a wind instrument.

Conclusions: IOP often rises after playing wind instruments, but similar or even higher IOP levels seem to occur during common other daily activities or at night. These peaks may be relevant for glaucomatous field progression and treatment of glaucoma patients.

Key Words: glaucoma, wind instruments, triggerfish sensing contact lens, continuous IOP measurement

( J Glaucoma 2017;26:923-928)

G laucoma is the second leading cause of irreversible blindness in the world. ${ }^{1}$ It is a neurodegenerative eye disorder with characteristic excavation of the optic nerve and visual field loss, in which intraocular pressure (IOP) is an important risk factor.

Received for publication March 2, 2017; accepted July 19, 2017

From the *Maastricht University Medical Center, University Eye Clinic Maastricht, Maastricht; $\uparrow$ Van Weel-Bethesda Hospital, Middelharnis; and $t$ Canisius Wilhelmina Hospital, Nijmegen, The Netherlands.

Supported by grants from Glaucoomfonds.

Disclosure: The authors declare no conflict of interest.

Reprints: Ronald M.P.C. de Crom, MD, Maastricht University Medical Center, University Eye Clinic Maastricht, P.O. Box 5800, 6202 AZ

Maastricht, The Netherlands (e-mail: r.de.crom@mumc.nl).

Copyright (C) 2017 Wolters Kluwer Health, Inc. All rights reserved.

DOI: 10.1097/IJG.0000000000000747
The influence of playing a wind instrument on IOP and its relation to the development of glaucoma in wind musicians is still not clearly elucidated. In addition, the magnitude of musicians who are at risk is not known. Both the type of wind instrument and the amount of time that people play their instrument could probably play a role in the development of ocular hypertension $(\mathrm{OHT})$ or glaucoma. ${ }^{2-4}$

There are only few studies on the effects on IOP related to playing a wind instrument. A study of Aydin et $\mathrm{al}^{2}$ showed an increase of IOP in musicians after playing for 90 minutes on their instrument. In a study by Schuman et $\mathrm{al}^{4}$ IOP and uveal thickness were measured by pneumotonometry and ultrasound bio microscopy during playing a wind instrument. In this study an increase in IOP in musicians was observed during the playing of both highresistance and low-resistance wind instruments and it was suggested that this IOP rise was the result of a Valsalva maneuver during playing, causing an increase in uveal volume. The level of IOP rise was dependent on the tone frequency, duration, and intensity of playing. They also found that high-resistance wind instrument players had a greater incidence of visual field loss than other musicians, related to the life hours of playing an instrument. A study by Schmidtmann et $\mathrm{al}^{5}$ investigated the effects of IOP and blood pressure of playing brass and wind instruments. They found a temporary elevation in IOP and blood pressure after playing tones on wind instruments, the magnitude depending on the tone frequency. In addition, 10 minutes of practicing showed a temporary IOP rise in both brass and woodwind instrument musicians.

The Sensimed Triggerfish sensing contact lens (Sensimed AG, Lausanne, Switzerland) is a wireless silicon contact lens sensor, which can be used for recording an IOP related pattern (in "arbitrary units") over a 24-hour period, with minimal disturbance to people's daily routines and during sleeping periods. In multiple studies ${ }^{6-14}$ the contact lens was shown to be safe and well tolerated in healthy subjects, glaucoma suspects, and glaucoma patients.

For our present study we wanted to investigate the impact of wind instrument playing on IOP under normal conditions (by simulating a real life situation) and in comparison to other daily activities to obtain information on the glaucoma risk for wind instrument players. Therefore, we firstly assessed the magnitude of IOP increase in wind instrument players under normal playing conditions. Secondly, we compared these findings to IOP fluctuations during 24-hour monitoring with the sensing contact lens, in an ambulatory mode and during normal activities (including practicing instruments at home, rehearsals, rest, meals, and at night) 


\section{METHODS}

\section{Subjects}

Members from 3 Dutch professional and 3 amateur symphony or wind orchestras were invited by letter to participate in the study. All participants were firstly asked to fill in a questionnaire on visual complaints and/or eye conditions resulting from and/or interfering with playing in the orchestra. ${ }^{15}$ After completing the questionnaire, interested wind instrument musicians were given the opportunity to undergo glaucoma screening with routine ophthalmologic examination and IOP-assessment after playing wind instruments. Interested musicians of other orchestras who were not invited could also participate in the glaucoma screening on their request (study part 1). From this group, randomly selected subjects were also asked to partake in 24-hour IOP monitoring with the Triggerfish sensing contact lens (study part 2).

Musicians who participated all gave their written informed consent to take part in the study, which was performed with approval of the Ethics committee of the Maastricht University Medical Center of the Netherlands. The study was conducted according to the principles of the Declaration of Helsinki (version 2008, Seoul) and in accordance with the Medical Research Involving Human Subjects Act (WMO).

All subjects underwent complete ophthalmic examination including visual acuity, Goldmann applanation tonometry, gonioscopy, pachymetry, anterior chamber assessment with anterior segment optical coherence (AS-OCT, Visante; Carl Zeiss Meditec Inc, Dublin, CA) and visual field testing with Humphrey perimetry (Carl Zeiss Meditec).

\section{Part 1: Ophthalmologic Examination and IOP-assessment After Playing Wind Instruments}

After determining baseline IOP with Goldmann applanation tonometry, participating subjects were asked to play a familiar music piece under normal conditions on their wind instruments uninterruptedly for 20 minutes. Directly (within $15 \mathrm{~s}$ ) after playing, IOP was measured again with Goldmann applanation tonometry.

\section{Part 2: 24-Hour IOP Monitoring With Triggerfish Sensing Contact Lens}

The subjects who agreed to participate in this part of the study underwent an ophthalmologic examination including corneal topography (Pentacam, Oculus Optikgeräte $\mathrm{GmbH}$ ) and Goldmann applanation tonometry. After examination, the size of the sensing contact lens was determined. For all subjects, sensors with a base curve radius of $8.7 \mathrm{~mm}$ were appropriate and chosen. The device was fitted, IOP recording initiated and continued for 24 hours, including the nocturnal period with undisturbed sleep. When applicable, subjects were instructed to instill IOPlowering medication according to their usual treatment schedule during IOP monitoring. In addition, subjects were asked to register their daily activities, music practicing/ rehearsals and sleeping time in an activity logbook. The Sensimed Triggerfish uses a circular strain gauge and additional telemetry technology embedded in a disposable silicone contact lens. This strain gauge detects circumferential fluctuations at the limbal-corneal transition corresponding with IOP fluctuations. ${ }^{16}$ The wireless sensor is powered from a battery containing portable recorder where monitoring data are stored for the duration of the 24-hour monitoring session. After 24 hours, the monitoring data were downloaded onto the ophthalmologist's computer using custom-made software. A qualitative fluctuation profile was produced, based on the median of the approximately 600 sensor output values recorded over 60 seconds once every 10 minutes during the monitoring session.

These qualitative fluctuation profiles were linked to the daily activities of the study subjects with help of their activity logbooks.

\section{RESULTS}

\section{Part 1: Ophthalmologic Examination and IOP-assessment After Playing Wind Instruments}

A total of 42 musicians (26 male) participated in this study, 11 professional ( 9 male) and 31 amateur (17 male) musicians (Table 1). Mean age was $50.2 \pm 13.1$ years (range, 22 to $74 \mathrm{y}$ ) for the total group, $42.5 \pm 8.0$ years for professional musicians, $52.9 \pm 13.5$ years for amateur musicians $(P=0.026)$. The mean number of instrument playing hours during a week was $11.4 \pm 9.9$ hours in the total group, $23.5 \pm 6.7$ hours in the professional group and $7.1 \pm 6.3$ hours in the amateur group $(P<0.001)$. The mean number of years playing a wind instrument was $29.5 \pm 16.2$ years in the total group, $33.2 \pm 7.1$ years in the professional group and $28.1 \pm 18.4$ years in the amateur group $(P=0.38)$. The instruments played on were: oboe ( 8 musicians), trumpet (5), French horn (3), bassoon (3), bugle (1), and tuba (1) (high-resistance instrument group) and clarinet (7 musicians), euphonium (5), trombone (4), saxophone (3), bagpipe (1) and flute (1) (low-resistance instrument group). Mean IOP before playing was $13.6 \pm 2.6 \mathrm{~mm} \mathrm{Hg}$ in the total group, $13.9 \pm 2.6 \mathrm{~mm} \mathrm{Hg}$ in the professional group and $13.5 \pm 2.6 \mathrm{~mm} \mathrm{Hg}$ in the amateur group $(P=0.51)$. Mean IOP change after playing for 20 minutes was $1.5 \pm 2.2 \mathrm{~mm} \mathrm{Hg}$ in the total group (range, -2 to 10$), 2.5 \pm 1.5 \mathrm{~mm} \mathrm{Hg}$ in the professional group (range, 0 to 4 ) and $1.1 \pm 2.3 \mathrm{~mm} \mathrm{Hg}$ in amateur group (range, -2 to 10$)(P=0.012)$. In the

TABLE 1. Demographics, Playing Characteristics, and Results of IOP Assessments Before and After Playing a Wind Instrument

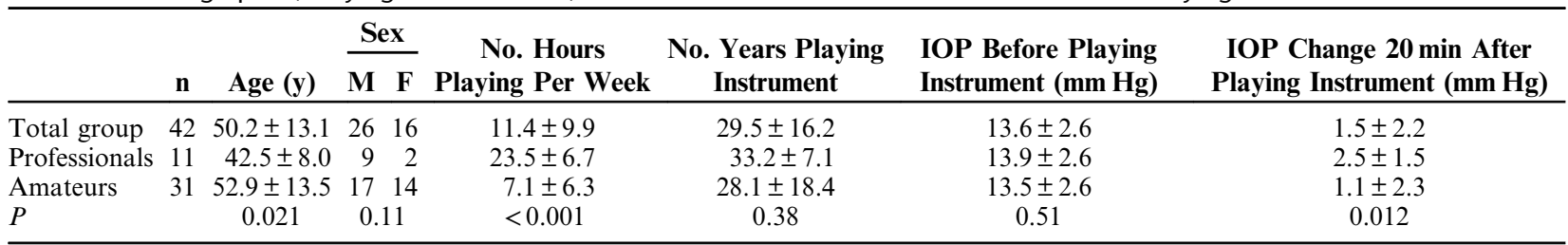

Values are indicated as means $\pm \mathrm{SD}$

$\mathrm{F}$ indicates female; IOP, intraocular pressure; $\mathrm{M}$, male. 
total group there was a correlation coefficient of $r=0.31$ $(P=0.005)$ between IOP change after 20 minutes of instrument playing and the total playing hours a week (Fig. 1). In the correlation calculation we excluded 1 subject with an IOP change of $10 \mathrm{~mm} \mathrm{Hg}$ after 10 minutes of playing, who stopped playing prematurely.

All participants with a rise in IOP had open angles on gonioscopy and anterior segment OCT. There were no statistically significant changes between the high-resistance instrument group versus the low-resistance group.

In the total group, 9 of 42 subjects were treated for glaucoma, 8 amateurs and 1 professional (Table 2). All of these subjects were already diagnosed with glaucoma and were treated by an ophthalmologist. In 8 subjects glaucoma was stable in 1 subject glaucoma was slightly progressive in 1 eye. Subjects in the glaucoma group were treated with topical IOL lowering medication (6 subjects; mean, 1.7 medications), laser peripheral iridotomy and laser iridoplasty (1 subject), trabeculectomy (1 subject) and 1 patient was currently off medication. Mean IOP in the glaucoma group versus the other participants was $14.6 \pm 3.0 \mathrm{~mm} \mathrm{Hg}$ and $13.3 \pm 2.4 \mathrm{~mm} \mathrm{Hg}(P=0.07)$. Mean deviation on the recorded visual fields in both groups were respectively $-7.0 \pm 7.5 \mathrm{~dB}$ and $-1.5 \pm 2.1 \mathrm{~dB}(P<0.001)$. Mean corneal thickness was $543 \pm 31 \mu \mathrm{m}$, with no statistical difference between glaucoma patients and the other participants. Mean IOP change after 20 minutes of playing a wind instrument was $1.6 \pm 3.3 \mathrm{~mm} \mathrm{Hg}$ (range, -2 to 10 ) in the glaucoma patients group and $1.4 \pm 1.8 \mathrm{~mm} \mathrm{Hg}$ (range, -2 to 5) in the nonglaucoma group $(P=0.77)$.

\section{Part 2: 24-Hour IOP Monitoring With Triggerfish Sensing Contact Lens}

The characteristics of the study participants for IOP monitoring with the Triggerfish sensing contact lens are shown in Table 3. All participants completed their 24-hour measurement. A total of 7 eyes were monitored of 6 wind instrument players, 1 professional, and 5 amateur musicians. There were 2 high-resistance wind instruments (hobo, horn,) and 5 low-resistance wind instruments (trombone, clarinet, tuba). Mean age of the subjects was $60.7 \pm 12.3$ years, with a range of 37 to 75 years. Five of 7 subjects had no preexistent ophthalmic pathology. Two of 7 subjects received prior treatment for glaucoma (1 subject trabeculectomy, 1 subject topical glaucoma medication and laser treatment).

Four musicians showed an IOP rise in study part 1 after playing 20 minutes on their wind instrument. The mean IOP increase was $3.75 \pm 0.38 \mathrm{~mm} \mathrm{Hg}$. For the others there was no change in IOP. The IOP fluctuation profiles as measured by the sensing contact lens of the participants are shown in Figure 2. The 24-hour monitoring sessions of 2 persons (\#3 and \#7) showed some disturbances: 1 session (\#3) did not record data for 2 hours and stopped recording 3 hour prematurely. The other session (\#7) did not record data for 6 hours.

In the IOP fluctuation profiles, IOP fluctuations during daily activities were seen in 5 of 7 profiles. Daily activities which led to a registered rise in IOP were cycling (11/17 daily activity fluctuations), walking (4/17 daily activity fluctuations), car driving (1/17) and washing/getting dressed/ making breakfast (1/17). IOP increases during daily

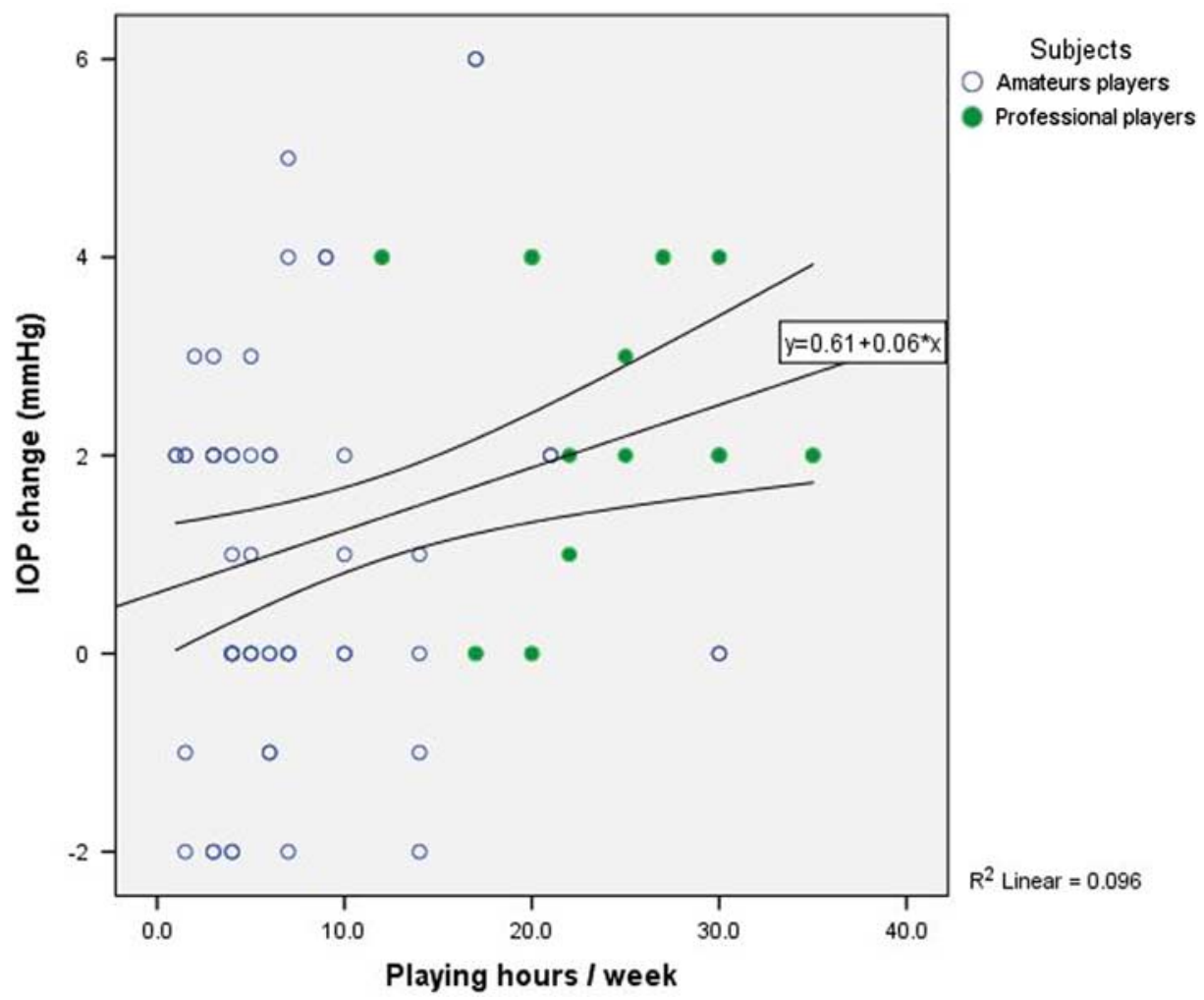

FIGURE 1. Association between playing hours/week and IOP change. The correlation coefficient between IOP change after 20 minutes of instrument playing and the total playing hours a week was $r=0.31(P=0.005)$. Most professional musicians had more playing hours a week and showed a larger IOP change in comparison with amateur musicians. 
TABLE 2. Characteristics of Glaucoma Patients Versus Other Participants

\begin{tabular}{lcccc}
\hline & n & $\begin{array}{c}\text { Mean Deviation } \\
\text { Visual Field }\end{array}$ & $\begin{array}{c}\text { IOP Before } \\
\text { Playing Instrument }\end{array}$ & $\begin{array}{c}\text { IOP Change 20 min } \\
\text { After Playing Instrument }\end{array}$ \\
\hline Total group & 42 & $-2.6 \pm 2.6$ & $13.6 \pm 2.6$ & $1.5 \pm 2.4$ \\
No glaucoma & 33 & $-1.5 \pm 2.1$ & $13.3 \pm 2.4$ & $1.44 \pm 1.79$ \\
Glaucoma & 9 & $-7.0 \pm 7.5$ & $14.6 \pm 3.0$ & $1.61 \pm 3.26$ \\
$P$ & & $P<0.001$ & $P=0.07$ & $P=0.77$ \\
\hline
\end{tabular}

Values are indicated as means $\pm \mathrm{SD}$

Mean deviation of visual field in Decibels (dB), intraocular pressure (IOP) in $\mathrm{mm} \mathrm{Hg}$ before playing a wind instrument and IOP change 20 minutes after playing.

activities were similar or often larger in comparison with the IOP rise while playing a wind instrument or during the night.

\section{DISCUSSION}

In this study we estimated the impact of wind instrument playing on IOP in the context of the participants' daily life situation. We want to mention the high prevalence of glaucoma in our study ( $9 / 42$ subjects), which can be explained by the fact that especially musicians who were already known in our or other departments wanted to participate in this study. We examined all participants and measured the IOP rise after 20 minutes of normal playing. The rationale of a 20-minute playing interval was an empirical decision, because there is no evidence concerning the optimal duration of a playing period that will be short or long enough to measure clinical relevant changes. We have chosen this playing interval for the reason that most players would practice for at least 20 minutes at a time, to reflect daily life conditions.

After 20 minutes of playing, we mainly found relative minor IOP increases, which may be because of the playing under physiological conditions that we asked our participants to do. We did not ask to over exert the participants as we aimed to simulate daily life conditions. However, although these changes were mostly small, they may be significant for individual participants, especially glaucoma patients. ${ }^{17}$ In professional musicians we found a larger IOP elevation when compared with the amateur musicians. In both groups we found a larger IOP rise in the subjects with glaucoma in comparison to subjects without glaucoma. We found no differences between high-resistance or low-resistance instrument players. Our study showed lower IOP elevations in comparison with the study of Schuman and colleagues. In their study IOP elevations of 20 and $22 \mathrm{~mm} \mathrm{Hg}$ were found in 2 patients with glaucoma. Their measurement conditions differed, as IOP measurements were taken in supine position and after prolonged playing of loud high notes, which may reflect extreme conditions. We were interested if a similar increase in IOP would be found during or after playing in more physiological conditions, which would more represent daily life. Because our subjects played for 20 minutes, the process of autoregulation may have played a role, but this assumption needs further proof. However, even during more physiological playing conditions, in our study also several patients showed IOP changes up to $10 \mathrm{~mm} \mathrm{Hg}$ after 20 minutes of playing.

Because IOP measurements could be influenced by corneal thickness and/or anterior segment anatomy we performed pachymetry and gonioscopy. There were no differences in pachymetry or anterior chamber angle width (no angle closure) between musicians with or without an IOP elevation after playing an instrument.

The difference between professional and amateur musicians in IOP elevation $(2.5 \mathrm{~mm} \mathrm{Hg}$ vs. $1.5 \mathrm{~mm} \mathrm{Hg}$ ) is surprising and difficult to explain but there is a difference in weekly playing hours and overall playing years. Professional musicians mentioned slightly more playing years (33.2 vs. $28.1 \mathrm{y})$, but much more weekly playing hours compared with amateurs $(23.5$ vs. $7.1 \mathrm{~h}$ ). For the total group we found a correlation between the IOP rise after 20 minutes of instrument playing and the total of playing hours per week (with both the IOP rise as the amount of playing hours highest in professionals). There were no correlations between baseline IOP before playing and IOP change after playing. It is assumed that professional musicians have better playing techniques. It may be that they have a more effective or more powerful way of playing leading to higher IOP levels, but it is unclear how this works, for example, by repeated Valsalva like maneuvers or otherwise. We need further study to elucidate the exact mechanisms. The differences in IOP fluctuation between subjects with and without glaucoma in the total group (1.61 vs. $1.41 \mathrm{~mm} \mathrm{Hg}$ ) are in line with the larger diurnal IOP fluctuations generally found in glaucoma patients when compared with normals. It may suggest impaired auto regulation of IOP.

With the Triggerfish sensing contact lens we monitored IOP for 24 hours to compare the IOP increase as a result of

TABLE 3. Participant Characteristics of 24-hours IOP Measurement With the Sensimed Triggerfish Sensing Contact Lens

\begin{tabular}{cccccccc}
\hline & Sex & Age $(\mathbf{y})$ & Instrument & Eye & IOP Change $\mathbf{( m m ~ H g )}$ & Ophthalmic History & Glaucoma Medication \\
\hline$\# 1$ & M & 37 & Trombone & OD & 4 & - & - \\
$\# 2$ & $\mathrm{~F}$ & 60 & Oboe & OS & 4 & - & - \\
$\# 3$ & $\mathrm{M}$ & 75 & Clarinet & OS & 3 & - & - \\
$\# 4$ & $\mathrm{~F}$ & 68 & Trombone & OD & 4 & Trabeculectomy & - \\
$\# 5$ & $\mathrm{~F}$ & 68 & Trombone & OS & 0 & Trabeculectomy, Re-trabeculectomy & timolol-dorzolamide \\
$\# 6$ & $\mathrm{~F}$ & 57 & French horn & OD & 0 & Iridoplasty, iridotomy & - \\
$\# 7$ & M & 59 & Tuba & OS & 0 & - & - \\
\hline
\end{tabular}

F indicates female; IOP, intraocular pressure; M, male; OD, right eye; OS, left eye 

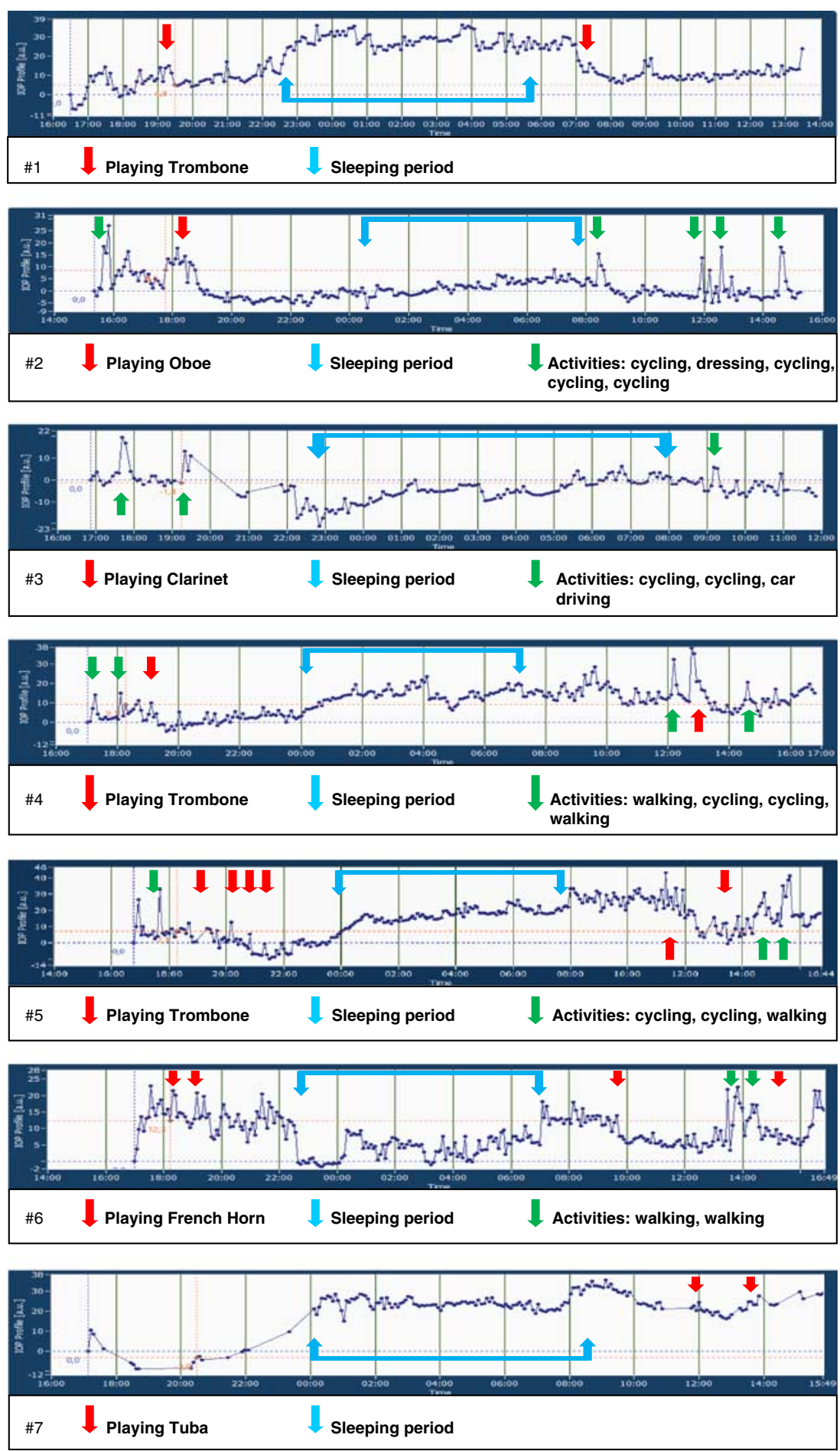

FIGURE 2. Results of 24-hour monitoring with the Triggerfish sensing contact lens. The IOP fluctuation profiles of each individual participant are shown. The red arrows indicate a period of playing a wind instrument, the green arrows a period of daily activity and the blue arrows a period of sleeping. The IOP fluctuation profile of participant \#1 shows 2 periods of playing a wind instrument and 1 period of sleeping. Profile \#2 shows 5 periods of daily activities, 1 period of playing a wind instrument and 1 period of sleeping. Profile \#3 shows 3 periods of daily activities, 1 period of sleeping and 1 period of measurement disturbance. Profile \#4 shows 2 periods of playing a wind instrument, 3 periods of daily activities and 1 period of sleeping. Profile \#5 shows 6 periods of playing a wind instrument, 3 periods of daily activities and 1 period of sleeping. Profile \#6 shows 4 periods of playing a wind instrument, 2 periods of daily activities and 1 period of sleeping. Profile \#7 shows 2 periods of playing a wind instrument, 1 period of sleeping and 1 period of measurement disturbance. 
wind instrument playing to other activities that may also influence IOP. Surprisingly, we found that the IOP increase during normal daily activities, such as cycling, was similar or higher than the increase resulting from playing. The activities subjects had performed included no strenuous activities, but were considered normal activities, for which it was not likely that a Valsalva was involved. No uphill or increased resistance walking or cycling was performed. In several cases, nocturnal IOP levels also exceeded IOP peaks from playing. One study subject participated in the study with both eyes. This participant was known with primary open angle glaucoma and showed a slightly progressive visual field loss in the right eye after trabeculectomy, whereas her left eye remained stable after trabeculectomy and retrabeculectomy. After playing in the first part of the study we found an IOP elevation of $4 \mathrm{~mm} \mathrm{Hg}$ in the right eye and a stable IOP in the left eye. With 24-hours IOP monitoring (Fig. 1, \#4 and \#5) we found IOP elevations in both eyes while playing a wind instrument and during other activities. Although this patient had a good (posteriorly located) bleb formation which did not influenced contact lens fitting, the effect of a created osteum by trabeculectomy, however, could influence the IOP measurement by Triggerfish lens by altered biomechanical condition of the eye. The measurements with the Triggerfish contact lens had some limitations. Only 6 persons (7 eyes) participated in 24 hour IOP monitoring. Although costly, we would have liked to include more participants in this part of the study. However, participants had to combine the monitoring with their daily life activities which also had to include practicing or rehearsing. This proved to be a too large hurdle for many subjects who found it too difficult to participate. Another limitation was the measurement disturbances in 2 of 7 measurements (\#3 and \#7). These disturbances were probably because of connection problems between the sensor and the antenna. In 1 session recording stopped prematurely, probably because of problems with the recorder. With regard to the increase or changes of contact lens signal with wind-instrument activity or other daily activities, we would like to make several remarks. We know that the total IOP level as measured by the Triggerfish contact lens is influenced by intraocular volume changes, biomechanical aspects of the eye and the IOP itself. It is thinkable that instrument playing or other activities (for example bicycle riding) could influence the output signal of the contact lens because of possible changes at the level of the corneoscleral junction. We have evaluated the different CLS curves in order to see if there were any changes in CLS signal during the specific activities, compared with the other measured points. The most obvious difference in CLS signal was found during the night, where the signal showed less disturbances and amplitude, an effect because of an absence of blinking during sleep and lack of activity by the subject. Because of the low number of Triggerfish measurements in our study (7 subjects) and measurement disturbances in 2 of 7 subjects, further statistical analysis of our data was not performed. Another limitation of this method is the fact that the IOP profile is generated in arbitrary units and not in $\mathrm{mm}$ $\mathrm{Hg}$. Only fluctuations in IOP can be observed and compared within 1 monitoring session. The exact IOP, for example, measured in $\mathrm{mm} \mathrm{Hg}$ by Goldmann tonometry, cannot be defined or extracted from the fluctuation profiles.

Despite this, our study shows that under normal conditions, IOP often increases after playing wind instruments. This IOP rise is mostly mild and although higher in professionals, probably not harmful for subjects without glaucoma. Glaucoma patients showed a larger IOP rise after playing compared with the other participants, which might be relevant for their risk of visual field progression. However, other daily activities were also found to lead to higher IOP levels. Therefore, it remains difficult to advise glaucoma patients with regard to wind instrument playing. When in doubt if IOP is under control, it can be helpful to invite them to the office and measure IOP after playing. In our study, several subjects showed IOP rises of 5 to $10 \mathrm{~mm} \mathrm{Hg}$ after 20 minutes of playing a wind instrument. In case of a significant IOP rise, treatment can be intensified to promote a more stable diurnal curve (eg, trabeculoplasty, incisional surgery). However, in advanced glaucoma cases or in patients who have progressive glaucoma we have to be careful in our advice with regard to continuing playing their wind instrument until we have more evidence.

\section{REFERENCES}

1. Resnikoff S, Pascolini D, Etya'ale D, et al. Global data on visual impairment in the year 2002. Bull World Health Organ. 2004:82:844-851

2. Aydin P, Oram O, Akman A, et al. Effect of wind instrument playing on intraocular pressure. J Glaucoma. 2000;9:322-324.

3. Markoff JI. High-resistance wind instruments and IOP. Ophthalmology. 2001;108:635-636.

4. Schuman JS, Massicotte EC, Connolly S, et al. Increased intraocular pressure and visual field defects in high resistance wind instrument players. Ophthalmology. 2000;107:127-133.

5. Schmidtmann G, Jahnke S, Seidel EJ, et al. Intraocular pressure fluctuations in professional brass and woodwind musicians during common playing conditions. Graefes Arch Clin Exp Ophthalmol. 2011;249:895-901.

6. Lorenz K, Korb C, Herzog N, et al. Tolerability of 24-hour intraocular pressure monitoring of a pressure-sensitive contact lens. J Glaucoma. 2013;22:311-316.

7. Mansouri K, Medeiros FA, Tafreshi A, et al. Continuous 24-hour monitoring of intraocular pressure patterns with a contact lens sensor: safety, tolerability, and reproducibility in patients with glaucoma. Arch Ophthalmol. 2012;130:1534-1539.

8. Tojo N, Hayashi A, Otsuka M, et al. Fluctuations of the intraocular pressure in pseudoexfoliation syndrome and normal eyes measured by a contact lens sensor. J Glaucoma. 2016;25: e463-e468.

9. Tojo N, Oka M, Miyakoshi A, et al. Comparison of fluctuations of intraocular pressure before and after selective laser trabeculoplasty in normal-tension glaucoma patients. J Glaucoma. 2014;23:e138-e143.

10. Tojo N, Otsuka M, Miyakoshi A, et al. Improvement of fluctuations of intraocular pressure after cataract surgery in primary angle closure glaucoma patients. Graefes Arch Clin Exp Ophthalmol. 2014;252:1463-1468.

11. Agnifili L, Mastropasqua R, Frezzotti P, et al. Circadian intraocular pressure patterns in healthy subjects, primary open angle and normal tension glaucoma patients with a contact lens sensor. Acta Ophthalmol. 2015;93:e14-e21.

12. Pajic B, Pajic-Eggspuchler B, Haefliger I. Continuous IOP fluctuation recording in normal tension glaucoma patients. Curr Eye Res. 2011;36:1129-1138.

13. Tan $\mathrm{S}, \mathrm{Yu} \mathrm{M}$, Baig $\mathrm{N}$, et al. Circadian intraocular pressure fluctuation and disease progression in primary angle closure glaucoma. Invest Ophthalmol Vis Sci. 2015;56:4994-5005.

14. Hollo G, Kothy P, Vargha P. Evaluation of continuous 24-hour intraocular pressure monitoring for assessment of prostaglandininduced pressure reduction in glaucoma. J Glaucoma. 2014;23:e6-e12.

15. Beckers HJM, Kooten-Noordzij MAWv, Crom RMPCd, et al Visual complaints and eye problems in orchestral musicians. Med Probl Perform Art. 2016;31:140-144.

16. De Smedt S, Mermoud A, Schnyder C. 24-hour intraocular pressure fluctuation monitoring using an ocular telemetry Sensor: tolerability and functionality in healthy subjects. J Glaucoma. 2012;21:539-544.

17. Heijl A, Leske MC, Bengtsson B, et al. Reduction of intraocular pressure and glaucoma progression: results from the Early Manifest Glaucoma Trial. Arch Ophthalmol. 2002;120:1268-1279. 